SLOVO, sv. 68 (2018), 1-34, Zagreb 2018.

\author{
Диана Дмитриевна БАЛАШЕВИЧ \\ Санкт-Петербургский государственный университет \\ dianad13@yandex.ru \\ Вячеслав Викторович КОЗАК \\ Институт лингвистических исследований \\ Российской академии наук (ИЛИ РАН) \\ Санкт-Петербургский государственный университет \\ viacheslav.kozak@gmail.com
}

$\begin{array}{lr}\text { Андрей Николаевич СОБОЛЕВ } & \text { UDK 003.072:003.349.1(497.5)”13” } \\ \text { Институт лингвистических исследований } & 27-876.3(497.5) " 13 ” \\ \text { Российской академии наук (ИЛИ РАН) } & \text { Izvorni znanstveni članak } \\ \text { Санкт-Петербургский государственный университет } & \text { Primljen: 31. prosinca 2016. } \\ \text { a.sobolev@spbu.ru } & \text { Prihvaćen: 29. studenoga 2018. }\end{array}$

\title{
ПАЛЕОГРАФИЧЕСКОЕ ОПИСАНИЕ ХОРВАТСКОЙ ГЛАГОЛИЧЕСКОЙ БУЛЛЫ ПАПЫ ГРИГОРИЯ ХІ ОРДЕНУ СВ. ПАВЛА ОТШЕЛЬНИКА*
}

Латинский текст консисториальной буллы, регламентирующей права и привилегии Ордена св. Павла Отшельника (Ордена паулинов), был подписан папой Григорием XI в Авиньоне в 1371 г. Хорватский перевод буллы осуществлен, вероятно, в одном из паулинских монастырей средневековой Хорватии. Единственный сохранившийся глаголический список перевода хранится в Коллекции рукописей и старых книг Национальной и университетской библиотеки Загреба (шифр R 4476). Рукопись не содержит сведений о месте и времени создания и по умолчанию датируется 70-ми годами XIV в. В настоящей работе, подготавливающей новое издание текста хорватского перевода

* Исследование выполнено при финансовой поддержке гранта Российского фонда фундаментальных исследований (проект »Издание памятников глаголической письменности из коллекции Берчича, хранящихся в Российской национальной библиотеке, и изучение их языка компьютерными методами«, № 18-012-00060 А). Авторы выражают сердечную благодарность д-ру Ивану Ботице за ценную информацию о хранении памятника в Загребской Национальной и университетской библиотеке, д-ру Ивану Косичу за помощь в работе с рукописью, д-ру Марице Чунчич, Антонио Магдичу, д-ру Амиру Капетановичу и д-ру Ане Шимич за помощь в реализации проекта и трем анонимным рецензентам за ценные рекомендации. 
буллы, описываются ее палеографические особенности. Рассматриваются начертания строчных, заглавных и декоративных графем, лигатур, инициала, надстрочных и строчных знаков. Приводятся сводные таблицы. Палеографическое описание рукописи позволяет провести несомненные параллели с глаголическими памятниками XIV-XV вв., однако более точное определение места и времени возникновения сохранившегося списка буллы будет возможно по мере исследования других языковых уровней и выработки критериев, дифференцирующих глаголическое письмо в рамках указанных временных и территориальных границ.

Ключевые слова: палеография, угловатая глаголица, булла, Григорий XI, XIV век, Хорватия, паулины

\section{1. ВВЕДЕНИЕ}

В 1371 г. в Авиньоне папой Григорием XI и кардиналами была подписана консисториальная булла Ордену св. Павла Отшельника (Ордену паулинов). Документ регламентировал права и привилегии паулинских монастырей na ug'rihb i po d'rugihb s'tranahb sego sveta. ${ }^{1}$

Орден св. Павла Отшельника был основан в Венгрии в XIII в. и быстро распространился на подконтрольных ей территориях. В XIV в. в Хорватии существовало уже несколько паулинских монастырей, как, например, находящиеся в районе залива Кварнер около города Сень монастыри св. Николы (хорв. Sv. Nikola), св. Спаса (хорв. Sv. Spas) или св. Елены (хорв. Sv. Jelena) (BOGOVIĆ 1988: 109). В одном из этих монастырей, возможно, и был осуществлен перевод буллы на хорватский язык.

Единственный известный на сегодняшний день список этого перевода, написанный хорватской угловатой глаголицей, хранится в коллекции рукописей и старых книг Национальной и университетской библиотеки Загреба под шифром R 4476 и представляет собой исписанный с одной стороны лист пергамена. У рукописи нет датировки, но на полях имеется дата »1371«, которая, однако, может быть поздним добавлением, ориентированным на время написания оригинала. Тем не менее в существующих работах исследователи по умолчанию исходят из гипотезы, что список хорватского перевода буллы возник вскоре после этой даты, так что она условно считается временем его создания (cp. MILČETIĆ 1916; KUZMIĆ 2009). Место создания перевода также неизвестно. И. Милчетич, основываясь только на наличии икавско-экавского рефлекса ятя, предположил, что перевод был выполнен в одном из паулинских монастырей, находящихся на севере территории распространения чакавского

1 'В Венгрии и других странах сего света'. 
наречия (MILČETIĆ 1916: 427; cp. KUZMIĆ 2009: 411). Памятник был издан И. Милчетичем в 1916 г. кириллицей (MILČETIĆ 1916). К сожалению, издание содержит значительное количество неточностей. Снимок рукописи напечатан в (AFANAS'EVA; KOZAK; SOBOLEV 2016).

Качество перевода тот же И. Милчетич оценивает достаточно низко: »Hrvatski je prijevod ropski, često nerazumliv«² (MILČETIĆ 1916: 426). Действительно, грамматическую структуру некоторых предложений можно объяснить ошибкой перевода или искажением текста при создании списка. Рассмотрим это утверждение на следующем примере перевода латинской фразы. ${ }^{3}$

1. Regularem vitam professis in perpetuum religiosam vitam eligentibus apostolicum convenit adesse praesidium, ne forte cujuslibet temeritatis incursus, aut eos a proposito revocet, aut robur, quod absit, sacrae religionis infringat (f. 544r).

2. regul'ni živots priêm'ši v(a) v(ê)ki · Regul'ni živots obiraûcimb · pristoit se da budetb nimь ap(usto)lska pomoĉb $\cdot$ a to zato da bi nikomu s'men'û protivnu $v$ pridan'i ili nihb ot dobra namišlen'ê otvede $\cdot$ ili moĉs ča ne budi s(ve)toi regulnosti raz'b'eniê .

В этом примере латинское предложение имеет грамматическую ос-

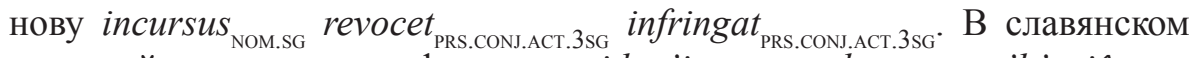

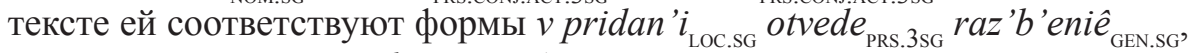
из которых только otvede имеет близкую грамматическую характеристику (настоящее время, 3-е л. ед. ч.). Грамматическая характеристика форм pridan 'i и raz'b'eniê не соответствует латинскому тексту и не может быть объяснена использованием той или иной синтаксической конструкции. Таким образом, в переводе у предложения фактически отсутствует грамматическая основа.

В научной литературе язык памятника определяется как чакавский (MILČETIĆ 1916; HERCIGONJA 1975: 130; KUZMIĆ 2009) или хорватский с чакавской диалектной основой (ср. DAMJANOVIĆ 2009: 351). Под данным термином обычно подразумевается чакавский литературный язык, или чакавщина, - хорватский литературный микроязык с чакавской диалектной основой. Этот язык бытовал в Хорватии в Средние века и Новое время и первоначально (до XV в.) использовался преимуществен-

2 'Хорватский перевод рабский, зачастую непонятный'.

3 Латинский текст приводится в орфографии и пунктуации издания К. Маллечича (MALLECHICH 1708) с корректурами по рукописи 1371 г. из собрания Ватиканской библиотеки Reg. Aven. 173, ff. 544r-545r. Хорватские примеры передаются латиницей. 
но при написании памятников юридического характера. C XV в. на чакавщине активно создаются произведения художественной литературы в Сплите (Марко Марулич), на о. Хвар (Петар Гекторович) и в Задаре (Петар Зоранич).

Настоящая работа выполнена в рамках совместного проекта сотрудников Института лингвистических исследований РАН (Санкт-Петербург), Санкт-Петербургского государственного университета и Старославянского института (Staroslavenski institut, Загреб). Проект посвящен комплексному исследованию буллы папы Григория XI паулинам, которое включает описание особенностей графики, орфографии, грамматики, лексики и техники перевода. Актуальность поставленных задач определяется необходимостью вновь ввести памятник в научный оборот, а также внести вклад в дискуссию о времени и месте его создания. Первым шагом этой исследовательской программы является описание палеографических особенностей рукописи. ${ }^{4}$

\section{2. ПАЛЕОГРАФИЧЕСКОЕ ОПИСАНИЕ}

\section{1. Предварительные терминологические замечания}

Палеографические особенности рукописи будут описаны в терминах графематики. Основным понятием графематики являются графема (ср. »фонема«, минимальная смыслоразличительная единица фонологии) (ŽAGAR 2013: 15; MARTI 2014: 1498). Согласно существующей традиции, в исследовании отождествляются понятия »графема« и »буква« (минимальная единица графической системы языка, обладающая тем или иным лингвистическим содержанием) и используются как терминологические дублеты (BÈSJA 1998: 117). Буквы памятника описываются в соответствии с их инвентарем, принятым в »Словаре церковнославянского языка хорватской редакции« (RCJHR 2000: XLVI). Буквы подразделяются на строчные и заглавные. Особой разновидностью заглавных букв является инициал (заглавная буква, вводящая определенный объем текста и украшенная миниатюрами или другими экстралингвистическими декоративными элементами). Промежуточное положение между буквами и инициалом занимают декоративные графемы, которые, не являясь инициалами, имеют яркие особенности начертания. Помимо отдельных

4 Параллельно при помощи созданного в рамках совместного проекта в Старославянском институте в Загребе web-приложения https:/grgur.stin.hr/ (авторы приложения - M. Чунчич и А. Магдич) в Санкт-Петербурге был проведен морфологический анализ текста буллы, результаты которого в настоящий момент готовятся к публикации. 
букв, в графическом инвентаре памятника выделяются лигатуры. Лигатура - графический знак, образованный путем соединения элементов двух графем (ср. BÈSJA 1998: 266).

Как можно увидеть из определения лигатуры, графемы и их соединения (лигатуры) состоят из определенного набора элементов, не имеющих самостоятельного лингвистического (графематического) содержания. Терминология, описывающая такие элементы, варьируется от исследования к исследованию. В данной работе при разработке языка описания за основу были взяты термины, использованные В. С. Голышенко при анализе графики кириллического Типографского Евангелия XII в. (GOLYŠENKO 2010). В результате, помимо понятий обыденного языка, как, например, »линия« или »треугольник«, в работе употребляются наименования »мачта«, »перекладина«, »сегмент« и некоторые другие, требующие специального пояснения.

1. Мачта - вертикальная линия в начертании буквы. Возможен »выгиб« мачты в ту или иную сторону (вплоть до образования дуги). В заглавных буквах мачта может удваиваться. В этом случае речь идет о толстой (двойной) мачте.

2. Перекладина - горизонтальная линия в начертании буквы.

3. Сегмент - замкнутое пространство с прямыми сторонами, образованное сочетанием мачт и перекладин.

Например, графема (p) представляет собой сочетание трех мачт и двух перекладин, при котором образуется один сегмент:

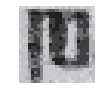

Рис. 1. Буква (p)

Fig. 1. Letter (p)

К более мелким элементам графем относятся »петли«, »черточки« и »усы«.

Петля - замкнутое линиями пространство, напоминающее сегмент, но с непрямой, округлой стороной. Например, петля, наряду с двумя мачтами (мачтой и дугой), содержится в графеме (c):

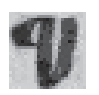

Рис. 2. Буква (c)

Fig. 2. Letter (c) 
Черточка - горизонтальная или вертикальная линия длиной в $1 / 4$ строки и менее. Например, графема (ㅅ) представляет собой вертикально расположенный прямоугольный сегмент в $2 / 3$ строки; его верхнюю сторону образует перекладина, от которой отходят вверх три равные черточки:

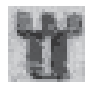

Рис. 3. Буква (र̂)

Fig. 3. Letter ( $\hat{\mathrm{c}})$

Элемент »ус« имеется только у буквы (̌̌) и представляет собой изогнутую линию, отходящую вверх и в сторону (налево или направо) от центра перекладины:

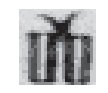

Рис. 4. Буква (̌̌)

Fig. 4. Letter (̌̌)

Под термином »слово《 в графическом анализе понимается »графическое слово«, т. е. последовательность графем, с двух сторон ограниченная пробелами. Графическое слово может, таким образом, состоять из нескольких слов (в лексикологическом смысле этого термина), например $a z^{\prime} v r h b$ (строка 12 слово 19; = a z'vrhb), izd'rêvi (строка 9 слово 13; = i z d'rêvi), kie (строка 5 слово 11; = ki e).

\section{2. Общие характеристики рукописи}

Хорватский перевод буллы папы Григория XI Ордену паулинов на данный момент известен в единственном списке, представляющем собой один лист пергамена размером примерно 60 х 30 см. Текст памятника написан с одной стороны листа угловатой глаголицей. Тип письма - устав. В процессе хранения лист был сложен в три раза, что отразилось на его сохранности: имеются линии сгиба, прочтение текста на которых затруднено или невозможно. В некоторых местах сгибов лист протерт до дыр. В целом сохранность документа хорошая. Края листа пергамена ровные, необтрепанные. Текст написан одной рукой. Исправления и помарки единичны.

Текст буллы занимает 43 строки, в строке от 117 до 160 графем, включая выносное (t) (исключение составляет последняя строка с 6 графемами). Во второй половине текста количество графем в строке резко возрастает с 117-130 до 130-160. При этом физическая длина строк остается примерно одинаковой. Высота строк 0.3-0.4 см. 
Текст написан одним цветом (черным), не имеет добавлений других цветов. В последних строках и на сгибах чернила выцвели и стали бледно-серыми (из-за плавности перехода оттенков нет основания предположить смену чернил). Иллюстрации отсутствуют.

Основной корпус текста содержит около 5500 графем, а также 6 графем за пределами основного корпуса текста: на полях над 13-м словом 1-й строки имеется глаголическая надпись ezusb, представляющая собой записанную глаголицей транскрипцию латинского слова Jesus.

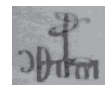

Рис. 5. Слово еzusb

Fig. 5. Word ezusb

Надпись сделана той же рукой, что и основной текст. При этом в 27-й строке встречается слово с тем же значением в род. п. в сокращении под титлом в характерном для хорватского языка фонетическом виде - is(usa).

Также над текстом имеется надпись 1371. inpovla $\langle\ldots\rangle \cdot$ ann [o]> • (?) более темными чернилами (появилась, скорее всего, позже). Сделана прописью, небрежно. Центральное слово вымарано, сверху добавлено исправление (невозможно прочитать).

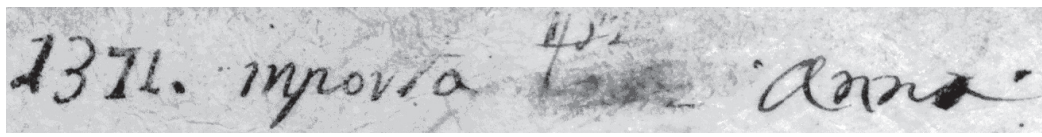

Рис. 6. Запись над текстом

Fig. 6. Inscription above the text

Памятник содержит и другие следы позднейшей (вероятно) работы. Так, строки 9-43 пронумерованы арабскими цифрами, написанными синим цветом. Теми же чернилами напротив 4-й и 7-й строк начерчены небольшие горизонтальные линии, пронумерованы графические слова первой строки, после первого слова 4-й строки проведена вертикальная черта, в 5-й строке над словом kie нарисованы три кружочка в ряд. Год в конце буллы подчеркнут двумя линиями.

\section{3. Описание букв}

Графический инвентарь буллы содержит 29 букв, 86 лигатур, инициал, строчные и надстрочные знаки. Ряд знаков имеет несколько вариантов написания, в т. ч. строчные, заглавные и декоративные варианты. 


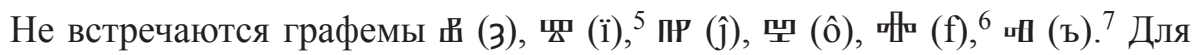
характеристики графико-орфографической традиции, в которой была написана рукопись, особенно важен факт отсутствия IIP ( $)$ ), поскольку в памятниках XIV в. у этой графемы уже появляется значение /j/ (ŠTEFANIĆ 1969: 14).

Для письма характерно обозначение как верхней, так и нижней линии строки, выраженное путем добавления перемычек. Ср., например, слова sveta во 2-й строке, učiniti в 33-й и gardinala (строка 42).

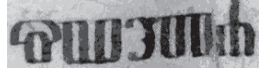

Рис. 7. Слово sveta

Fig. 7. Word sveta

\section{क\$सेमाएप}

Рис. 8. Слово ис̌initi

Fig. 8. Word učiniti

\section{quthethisuturoth}

Рис. 9. Слово gardinala

Fig. 9. Word gardinala

В других случаях перемычек может быть две, как, например, в примере из 38-й строки:

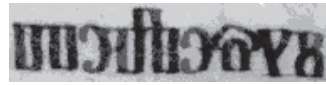

Рис. 10. Слово telesni

Fig. 10. Word telesni

Двухлинейный тип письма - признак развитого устава XIV в. (ŠTEFANIĆ 1969: 13).

\footnotetext{
5 В отличие от ш.

6 В отличие от ф.

7 Также отсутствуют сочетания 맹, 매포 и 매프.
} 


\subsection{1. Строчные буквы}

(A) $(a z b-a z)^{8}$

\section{ih}

Рис. 11. Буква (а)

Fig. 11. Letter (a)

Аз представляет собой три мачты, две по краям (3/4 высоты строки) соединены сверху перекладиной, центральная мачта чуть выступает за верхнюю границу строки. Графема два раза употребляется в числовом значении: в строке 42 без титла с двумя точками и в строке 43 в виде лигатуры с $\ddot{i}$ под общим титлом и точками по обе стороны.

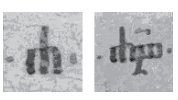

Рис. 12. Буква (а) в числовом значении

Fig. 12. Letter (a) as a numeral

(B) (buky-buki)

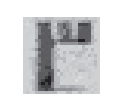

Рис. 13. Буква (b)

Fig. 13. Letter (b)

Буки состоит из мачты и двух перекладин, отходящих от нее вправо. Верхняя перекладина находится на высоте примерно в 4/5 - 2/3 строки. От нее в центре и справа отходят две одинаковые вертикальные черточки высотой соответственно в $1 / 5-1 / 3$ строки. Линия нижней перекладины тонкая, иногда плохо различимая.

(V) (vêdê-vjedje)

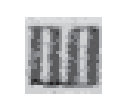

Рис. 14. Буква (v)

Fig. 14. Letter (v)

Веде имеет два одинаковых вертикально вытянутых сегмента, соединенных перекладиной внизу.

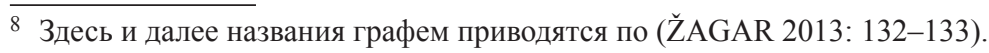


(G) (glagoli-glagoli)

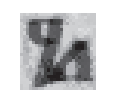

Рис. 15. Буква (g)

Fig. 15. Letter (g)

Глаголи состоит из мачты, чуть выгнутой дугообразно вправо. Сверху в левую сторону отходит маленькая петля (1/3 строки) с прямым углом, верхняя сторона которого обычно слабее прорисована. Мачта спускается чуть ниже строки, образуя »хвостик«. Из нижнего угла мачты вправо отходит сегмент в виде равностороннего треугольника размером в $3 / 4$ строки. Нижняя сторона треугольника обычно слабее прорисована.

(D) (dobro-dobro)

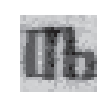

Рис. 16. Буква (d)

Fig. 16. Letter (d)

Добро состоит из двух прямоугольных сегментов: первый занимает строку целиком, второй, квадратный, - нижнюю половину строки; элементы соединены ровной перекладиной сверху, от которой под прямым углом отходит мачта, соединяясь с левой стороной второго сегмента.

(E) $(e s t b-j e s t)$

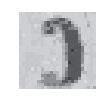

Рис. 17. Буква (е)

Fig. 17. Letter (e)

Есть представляет собой вертикальный овал, разорванный с левой стороны и с загнутыми друг к другу концами. Маленький язычок почти не виден или отсутствует. Допускается в некоторых случаях слитное написание (е) с предшествующей/последующей буквой, что, однако, не превращает ее в лигатуру (см., например, строка 2 слово 3, строка 11 слово 10, строка 19 слово 8).

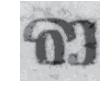

Рис. 18. Сочетание se

Fig. 18. Combination se 
Встречается в цифровом значении с ї под титлом в окружении точек в строке 42.

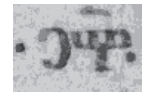

Рис. 19. Буква (е) в числовом значении

Fig. 19. Letter (e) as a numeral

(Ž) (živête-živjete)

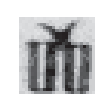

Рис. 20. Буква (̌̌)

Fig. 20. Letter (̌̌)

Живете представляет собой два одинаковых вертикально вытянутых сегмента, соединенных сверху перекладиной, из центра которой вверх расходятся »усики«. Левый »ус« ниже, чем правый, на протяжении всей рукописи.

(Z) (zemlê-zemlja)

\section{Don}

Рис. 21. Буква (z)

Fig. 21. Letter (z)

Земля представляет собой два сегмента, первый из которых - мачта, на концах соединенная с дугой. Чуть выше центра от мачты вправо отходит перекладина, присоединяющая второй сегмент в виде квадрата в $1 / 2$ строки. Перекладина является верхней стороной квадрата. Мачта чуть выступает за пределы нижней линии строки. Графема употребляется также под титлом в числовом значении в строке 42, с двух сторон от графемы стоят точки.

\section{Du-}

Рис. 22. Буква (z) в числовом значении

Fig. 22. Letter (z) as a numeral

(Ï) $(i(i \check{z} e)-i(i z ̌ e))$

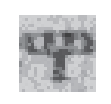

Рис. 23. Буква (i)

Fig. 23. Letter (i) 
(Ï) имеет мачту до середины строки, над ней длинная перекладина, от которой вверх отходят четыре черточки. Сверху черточки соединены тонкой перекладиной, образуя три небольших сегмента. Встречается два раза в цифровом значении в строках 42 и 43 , во втором случае - в составе лигатуры.

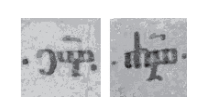

Рис. 24. Буква (i) в числовом значении

Fig. 24. Letter (i) as a numeral

(I) (ǐze (i) - iže (i))

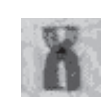

Рис. 25. Буква (i)

Fig. 25. Letter (i)

(I) состоит из двух расположенных друг над другом элементов, напоминающих равнобедренные треугольники и имеющих общую точку вершинных углов. Линии боковых сторон слегка округлые. Верхний треугольник меньше нижнего или равен ему. Также встречается начертание, где правые боковые стороны треугольных элементов образуют почти прямую линию (например, строка 14 слово 1):

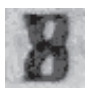

Рис. 26. Буква (i) (вариант)

Fig. 26. Letter (i) (variant)

(K) (kako-kako)

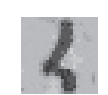

Рис. 27. Буква (k)

Fig. 27. Letter (k)

(K) представляет собой две дуги, расходящиеся чуть ниже середины строки. Верхняя, выгнутая, обращена вверх, а нижняя, с более крутым изгибом, - вниз. Может писаться слитно с предшествующей буквой или отдельно от нее вне зависимости от буквы. Так, например, сочетание $s k$ в строке 1 написано слитно, а в строке 7 - раздельно. 


\section{จर $\mathbb{2}$}

Рис. 28. Сочетание $s k$

Fig. 28. Combination $s k$

(L) (lûdie-ljudje)

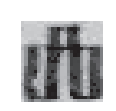

Рис. 29. Буква (1)

Fig. 29. Letter (1)

(L) представляет собой три прямоугольных сегмента. Два идентичных нижних соединены перекладиной, на которой в ширину пробела располагается третий сегмент в виде маленького квадрата (примерно 1/2 высоты нижних сегментов). Квадратик целиком выступает над строкой (исключения составляют лигатуры, где (1) может целиком помещаться в строку).

$$
\text { (M) (myslite - mislite) }
$$

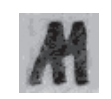

Рис. 30. Буква (m)

Fig. 30. Letter (m)

Графема (m) в памятнике восходит не к оригинальной глаголической букве, но к соответствующей букве латинского (или кириллического) алфавитов (ср. ÂGIČ 1911: 196). Первая мачта наклонена справа налево (см. сверху вниз), две другие также под наклоном, но еле заметным и в другую сторону. Соответственно, две первые смыкаются наверху, а третья присоединена ко второй небольшой перемычкой, параллельной первой мачте. Встречается в трех лигатурах в инновационном написании ( $m u$ в строке 40, ma в строке 28, то в строке 23) и в глаголическом написании в лигатуре $m l$ (в строке 24) (см. раздел о лигатурах).

(N) $(n a \check{s} b-n a \check{s})$

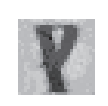

Рис. 31. Буква (n)

Fig. 31. Letter (n)

(N) имеет наклоненную влево мачту. Петля в 1/2 строки отходит сверху под прямым углом и дугообразно возвращается к мачте, оставляя на 
ней небольшую насечку. Употребляется и в числовом значении под титлом и в окружении точек.

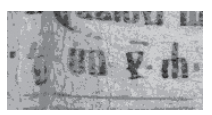

Рис. 32. Буква (n) в числовом значении

Fig. 32. Letter (n) as a numeral

(O) $($ onb - on)

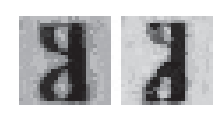

Рис. 33. Буква (о)

Fig. 33. Letter (o)

(О) состоит из двух небольших петель, расположенных с левой стороны сверху и снизу мачты. Петли не полностью округлые, а имеют две прямые стороны, соединяющиеся под прямым углом. Третья сторона округлая. Верхняя петля чуть меньше или равна нижней. Петли могут и смыкаться, и не смыкаться.

(P) (pokoi-pokoj)

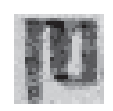

Рис. 34. Буква (p)

Fig. 34. Letter (p)

Графема (p) представляет собой мачту, сверху соединенную перекладиной с прямоугольным сегментом. Сегмент высотой со строку, а мачта чуть спускается со строки.

(R) $(r b c i-r c i)$

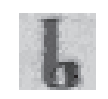

Рис. 35. Буква (r)

Fig. 35. Letter (r)

(R) имеет прямую мачту, маленькую петлю снизу (примерно 1/4 высоты строки, может быть $1 / 3$ и $1 / 2$ ).

(S) (slovo - slovo)

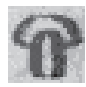

Рис. 36. Буква (s)

Fig. 36. Letter (s) 
(S) представляет собой вертикально расположенный прямоугольный сегмент, на котором находится горизонтально лежащий овал. Верхняя часть сегмента на уровне примерно 1/2 высоты строки разрывает нижнюю линию овала. Овал располагается симметрично, не смещаясь в левую или правую сторону.

В 3-м слове 33-й строки писец ошибся, слив (t) и (v) в лигатуру, а затем превратил второй сегмент (v) в (s), вследствие чего »шапочка« (s) оказалась смещенной набок.

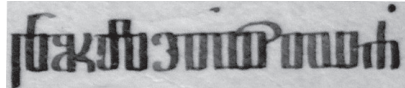

Рис. 37. Слово proklet'stva

Fig. 37. Word proklet'stva

(T) (tvrbdo-tvrdo)

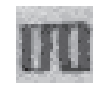

Рис. 38. Буква (t)

Fig. 38. Letter (t)

(Т) имеет два одинаковых вертикально вытянутых сегмента, соединенных перекладиной сверху. Один раз графема употребляется в числовом значении под титлом и с точками с двух сторон (см. выше).

Выносное (t) представляет собой перекладину с двумя небольшими смотрящими вниз петлями по краям, появляется обычно после (о) ${ }^{9}$ и всегда на грани морфем (чаще всего в предлогах, например ot bližnihb, или приставках, например otiti).

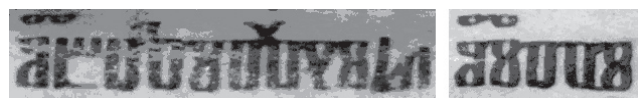

Рис. 39. Слова ot bližnihb и otiti

Fig. 39. Words ot bližnihb and otiti

При этом непосредственно после выносного (t) может следовать (t) строчное, например ottačasku, или ( $\mathrm{t})$ в составе лигатуры, например ot toga.

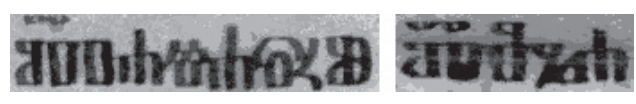

Рис. 40. Слова ottačasku и ot toga

Fig. 40. Words ottačasku and ot toga

9 Можно провести аналогию с кириллическими памятниками, где предлог и приставка ot часто пишутся через $\ddot{w}$. 
Единственный пример, когда выносное $(\mathrm{t})$ употребляется в позиции не после (o), - форма $b r(a) t(i) \hat{e}$ в строках $31,32,34$.

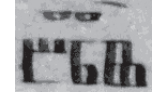

Рис. 41. Слово $\operatorname{br}(a) t(i) \hat{e}$

Fig. 41. Word $b r(a) t(i) \hat{e}$

(U) $(u k b-u k)$

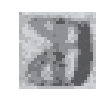

Рис. 42. Буква (u)

Fig. 42. Letter (u)

(U) представляет собой букву (о), к которой справа примыкает выгнутый сегмент, разделенный на две части поперечной перекладиной.

(F) $(f r b t b-f r t)$

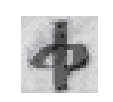

Рис. 43. Буква (f)

Fig. 43. Letter (f)

(F) имеет вертикальную мачту и две петли по обе ее стороны в середине. Левая петля тоньше и имеет менее округлую форму. Буква заимствована из греческого алфавита и в глаголице имеет два прототипических начертания: ф и 㕧 (cp. ÂGIČ 1911: 202). В тексте буллы употребляется только первое из них.

(H) (hêr (her[uvim]ъ) - hjer)

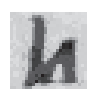

Рис. 44. Буква (h)

Fig. 44. Letter (h)

(Н) состоит из мачты, чуть выгнутой дугообразно вперед. По обоим концам мачты есть насечки, нижняя из которых более отчетлива и незначительно »свешивается« со строки. Из нижнего угла мачты вправо отходит сегмент в виде равностороннего треугольника размером в $3 / 4$ строки. Нижняя сторона треугольника представляет собой тонкую, иногда едва видную, линию. 


$$
\text { (र) }(\hat{c} a-\check{s} t a)
$$

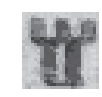

Рис. 45. Буква (र̂)

Fig. 45. Letter ( $\hat{c})$

( $\hat{\mathrm{C}})$ представляет собой вертикально расположенный прямоугольный сегмент в $2 / 3$ строки, на его верхней стороне лежит перекладина, от которой отходят вверх три равные черточки.

(C) $(c i-c i)$

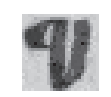

Рис. 46. Буква (c)

Fig. 46. Letter (c)

(C) представляет собой мачту с небольшой петлей влево наверху. От мачты снизу вверх вправо отходит дуга под острым углом.

(亡̌) $(\check{c} r b v b-\check{c} r v)$

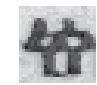

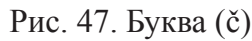

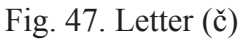

(С̆) имеет нижний сегмент в виде квадрата высотой в $1 / 2$ строки, над ним горизонтальная перекладина, от которой вверх отходят две близко расположенные петли. Из каждой из них вверх проведена черточка. Черточки расположены не симметрично, а слегка смещены влево.

(亡̌S) $(\check{s} a-\check{s} a)$

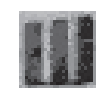

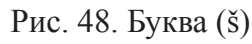

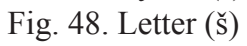

(ঙ̌) имеет три почти равных мачты, соединенных внизу перекладиной.

(b) $(\text { jerb }- \text { jor })^{10}$

Рис. 49. Буква (ь)

Fig. 49. Letter (ь)

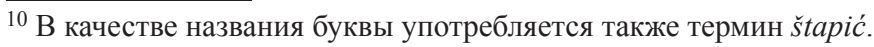


(b) представляет собой прямую одиночную мачту во всю строку. После графем (h), (d) и (z) может быть ниже, в 4/5 строки. См., например, 2-е слово 2-й строки.

\section{क्रufinthh}

Рис. 50. Слово s'tranahb

Fig. 50. Word s'tranahb

( $\hat{E})(\hat{e} t b-j a t)$

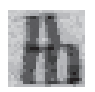

Рис. 51. Буква (ê)

Fig. 51. Letter (ê)

$(\hat{E})$ состоит из трех сегментов. Два нижних имеют общую сторону и одинаковую высоту. Почти треугольный верхний находится над нижним левым сегментом. Он равен нижним по высоте, а его правая сторона чуть наклонена.

(U) $(\hat{u}(\check{z} e) / j u(\check{z} e)-j u(\check{z} e))$

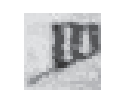

Рис. 52. Буква (û)

Fig. 52. Letter ( $\hat{u})$

(Û) представляет собой три вертикальные мачты, соединенные сверху горизонтальной перекладиной. Первая доходит до конца строки, вторая не доходит $1 / 6$, третья - 1/3. Снизу мачты соединены наклонной линией, выступающей слева на 2/5 - 1/2 своей длины и, соответственно, немного выходящей за нижнюю линию строки.

\subsection{2. Заглавные буквы}

Заглавные буквы непоследовательно встречаются после точек и знаков параграфов и обычно обозначают начало нового сегмента текста.

(A) $(a z b-a z)$

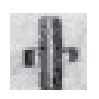

Рис. 53. Буква (А)

Fig. 53. Letter (A) 
(А) (4 употребления) представляет собой две параллельные мачты, соединенные перемычками сверху и снизу и выступающие над и под строкой. Вместе эти элементы образуют единую толстую мачту. Посередине мачты имеются две небольшие петли, обращенные соответственно в левую и правую сторону. Подобное написание заглавных букв с характерной двойной (толстой) линией встречается и в латинских памятниках. Начертание заглавной буквы (А) можно считать более архаичным, поскольку оно напоминает строчную (а) округлой глаголицы.

(B) (buky-buki)

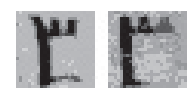

Рис. 54. Буква (В)

Fig. 54. Letter (B)

(B) (2 употр.) имеет более длинную, чем у строчной, мачту, в некоторых случаях слегка выгнутую вправо. Снизу вправо отходит перекладина, которая также может быть слегка выгнута.

(V) (vêdê-vjedje)

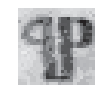

Рис. 55. Буква (V)

Fig. 55. Letter (V)

(V) (2 употр.), в отличие от строчной (v), не имеет двух соединенных сегментов. Буква состоит из двух мачт, соединенных снизу перекладиной. В верхней части мачт находятся две небольшие петли, смотрящие в противоположные стороны. Буква чуть спускается со строки. Вертикальные линии стилистически напоминают двойную (толстую) мачту в (А). Начертание графемы сходно c (v) в округлой глаголице старославянских памятников.

(D) (dobro-dobro)

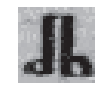

Рис. 56. Буква (D)

Fig. 56. Letter (D)

(D) (6 употр.) фактически представляет собой перевернутую (V). Буква состоит из двух мачт, соединенных вверху перекладиной. В нижней части мачт находятся две небольшие петли, смотрящие в противоположные стороны. Начертание графемы напоминает облик (d) в округлой глаголице старославянских памятников. 
(Z) (zemlê-zemlja)

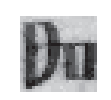

Рис. 57. Буква (Z)

Fig. 57. Letter (Z)

Заглавная (Z) (1 употр.) несколько крупнее строчной. Буква выступает под и над строкой.

(I) $(i(\ddot{z} e)-i(i \check{z} e))$

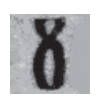

Рис. 58. Буква (I)

Fig. 58. Letter (I)

Заглавная графема (I) (17 употр.) больше строчной, опускается чуть ниже строки и поднимается немного выше нее, нижний сегмент значительно длиннее верхнего.

(K) $(k a k o-k a k o)$

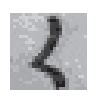

Рис. 59. Буква (К)

Fig. 59. Letter (K)

(K) (4 употр.) больше строчной, свешивается со строки и выступает над ее верхней границей.

(M) (myslite - mislite)

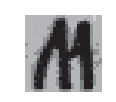

Рис. 60. Буква (М)

Fig. 60. Letter (M)

(M) (1 употр.) идентична строчной, но больше нее и выступает за нижнюю и верхнюю границы строки.

(N) $(n a \check{s} b-n a \check{s})$

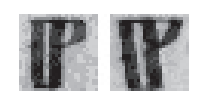

Рис. 61. Буква (N)

Fig. 61. Letter (N)

(N) (3 употр.) представляет собой двойную (толстую) мачту, расположенную перпендикулярно строке или под небольшим наклоном, с маленькой петлей сверху. 
(O) $($ onb -on)

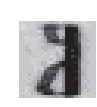

Рис. 62. Буква (O)

Fig. 62. Letter $(\mathrm{O})$

(O) (1 употр.) идентична строчной, но чуть больше и немного выступает за строку вверху и внизу.

(P) (pokoi-pokoj)

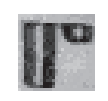

Рис. 63. Буква (Р)

Fig. 63. Letter $(\mathrm{P})$

(Р) (1 употр.) опускается ниже линии строки, состоит из двойной (толстой) мачты, верхняя горизонтальная линия мачты продолжается вправо, образуя перекладину. На конце перекладины имеется небольшая петля, обращенная вниз.

(R) $(r b c i-r c i)$

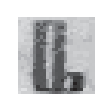

Рис. 64. Буква (R)

Fig. 64. Letter (R)

(R) (2 употр.) представляет собой укрупненный вид строчной с толстой мачтой, выступающей над и под строкой.

(S) (slovo - slovo)

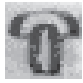

Рис. 65. Буква (S)

Fig. 65. Letter (S)

Заглавная (S) (2 употр.) отличается от строчной тем, что ее вертикальный сегмент длиннее и спускается чуть ниже строки.

(T) $($ tvrbdo-tvrdo)

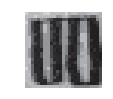

Рис. 66. Буква (Т)

Fig. 66. Letter $(\mathrm{T})$

Заглавная (T) (2 употр.) подобна строчной, но больше нее и выступает за нижнюю границу строки. 
(H) (hêr (her[uvim] b) - hjer)

Заглавная $(\mathrm{H})$ употребляется один раз в составе лигатуры »Но« (см. рис. 70$)$; в отличие от строчной (h), она имеет толстую мачту.

(亡) $(\check{c} r b v b-\check{c} r v)$

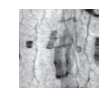

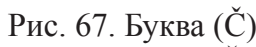

Fig. 67. Letter ( $\breve{C})$

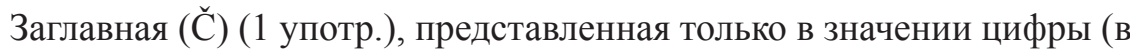
строке 42), идентична строчной, но прямоугольный сегмент значительно выходит за нижнюю границу строки.

Таким образом, в инвентаре заглавных букв отсутствуют графемы $(\mathrm{G}),(\mathrm{E}),(\check{\mathrm{Z}}),(\hat{\mathrm{I}}),(\mathrm{L}),(\mathrm{U}),(\mathrm{F}),(\mathrm{H}),(\hat{\mathrm{C}}),(\mathrm{C}),(\breve{\mathrm{S}}),(\hat{\mathrm{E}})$ и $(\hat{\mathrm{U}})$.

\subsection{3. Декоративные буквы}

"Декоративные буквы« - графемы с удлиненными мачтами, украшенными завитками. Есть только четыре таких знака в трех первых словах буллы, один из них выступает в составе лигатуры.

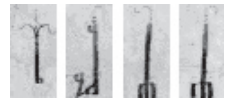

Рис. 68. Декоративные буквы

Fig. 68. Decorative letters

Подобное оформление графем первой строки с помощью удлиненных мачт и завитков характерно и для латинских памятников этого периода, о чем, в частности, свидетельствуют списки других документов Григория XI паулинам. ${ }^{11}$

\section{4. Инициал}

Первая графема в тексте буллы представляет собой инициал.

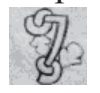

Рис. 69. Инициал (G)

Fig. 69. Initial (G)

\footnotetext{
${ }^{11}$ Некоторые из таких документов опубликованы онлайн (URL: http:/monasterium.net/ mom/AT-HHStA/OSPPE/1371_X_07/charter (19. 06. 2018), http://monasterium.net $/ \mathrm{mom} /$ AT-HHStA/OSPPE/1371_X_10/charter (19.06. 2018).
} 
Инициал (G) - знак высотой в 3 строки, сверху совпадает с верхней границей 1-й строки, снизу - с нижней границей третьей строки. В ширину соответствует одной-двум буквам. На концах имеет »узлы«, украшенные листьями.

\section{5. Лигатуры}

В графическом инвентаре буллы богато представлены лигатуры. В основном в состав лигатур входят строчные буквы, но в редких случаях после точки может выступать и заглавная буква, например в лигатуре »Н« (строка 36):

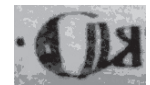

Рис. 70. Лигатура »Но« после знака параграфа

Fig. 70. Ligature $» H o \ll$ after a paragraph sign

Лигатуры употребляются несистемно. Встречающаяся несколько раз форма prepovedamo содержит в разных случаях от одной до четырех лигатур.

\begin{tabular}{|c|c|c|c|c|}
\hline Строка & Транслитерация & Слово в тексте & $\begin{array}{c}\text { Лигатуры } \\
\text { в слове }\end{array}$ & $\begin{array}{l}\text { Перемычки } \\
\text { в слове }\end{array}$ \\
\hline $12-13$ & prepovedamo & 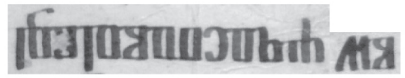 & $\mathrm{pr}$ & prepov, eda, mo \\
\hline 14 & prepov(e)damo & for|rimintary & pr, vda & $\begin{array}{l}\text { epov (перемычка } \\
\text { между } е \text { и } p \text { не } \\
\text { доведена до } e \text { ), mo } \\
\text { (перемычка не } \\
\text { доведена до } m \text { ) }\end{array}$ \\
\hline 26 & prepovedamo & 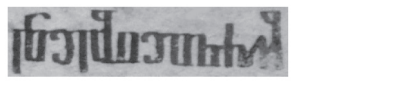 & $\begin{array}{l}\text { pr, pov, } \\
\text { da, mo }\end{array}$ & $\begin{array}{l}\text { prepov, eda, am } \\
\text { слиты }\end{array}$ \\
\hline 33 & prepovedamo & 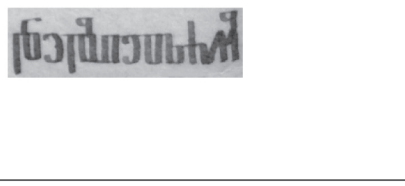 & $\begin{array}{l}\text { pr, pov, } \\
\text { da, mo }\end{array}$ & $\begin{array}{l}\text { epoveda } \\
\text { (перемычка } \\
\text { между } е \text { и } p \text { не } \\
\text { доведена до } е \text { ), am } \\
\text { слиты }\end{array}$ \\
\hline
\end{tabular}

Таблица 1. Лигатуры в словоформе prepovedamo

Table 1. Ligatures in form prepovedamo 
Лигатуры »la« и »bla« употреблены в формах oblas'tiû в строках 21 и 36 и не употреблены в остальных случаях (при этом в строках 14, 23, $31,{ }^{12} 32,38,{ }^{13} 39^{14} » 1 \ll$ и »а« соединены перемычкой).

\begin{tabular}{|c|c|c|c|c|}
\hline Строка & Транслитерация & Слово в тексте & $\begin{array}{c}\text { Лигатуры } \\
\text { в слове }\end{array}$ & $\begin{array}{c}\text { Перемычки } \\
\text { в слове }\end{array}$ \\
\hline 5 & oblastiû & 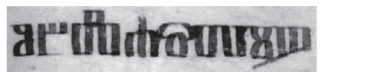 & - & tîu \\
\hline 14 & oblastiû & drilith & - & $l a, t i \hat{u}$ \\
\hline 21 & oblas 'tîu & ariftiondras & la & tîu \\
\hline 23 & oblas 'tîu & ge्यfitmingाए & - & la, tî̀ \\
\hline 31 & oblastb & & - & $l a, s$ и $t$ слиты \\
\hline 32 & oblastiû & ariftutfovu\&! & - & la, stîu \\
\hline 36 & oblastiû & ivluglo & bla & tîu \\
\hline 38 & oblastniki & Aulless & - & la, stni, ki \\
\hline 39 & oblastb & cyerib & - & $\begin{array}{l}l a, \text { перемычка между } \\
s \text { и } t \text { не доведена до } s\end{array}$ \\
\hline
\end{tabular}

Таблица 2. Лигатуры в словоформах с корнем oblast-

Table 2. Ligatures in the form oblast-

\footnotetext{
12 Форма oblastb.

${ }^{13}$ Форма oblastniki.

14 Форма oblastb.
} 


\section{6. Прочие строчные и надстрочные знаки}

В рукописи буллы употребляется два строчных знака, не являющихся буквами: точка и знак параграфа.

Точка

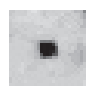

Рис. 71. Точка

Fig. 71. Point

Точка пишется в середине строки. После нее могут стоять как строчные, так и заглавные буквы.

Знак параграфа

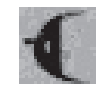

Рис. 72. Знак параграфа

Fig. 72. Paragraph sign

Знак параграфа представляет собой полукруг, раскрытый вправо с закрашенным сегментом в центре дуги, но с оставленной белой точкой/ черточкой посередине сегмента. После знака параграфа могут стоять как строчные, так и заглавные буквы.

К надстрочным знакам в рукописи буллы относятся паерки и титла.

\section{Паерок $^{15}$ (вариант 1)}

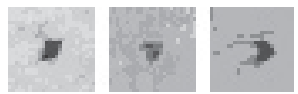

Рис. 73. Паерок (вариант 1)

Fig. 73. Paerok (variant 1)

Паерок представляет собой точку с почти непрочерченной предшествующей линией.

15 Паерок стоит над словом на месте этимологического редуцированного (prisež'nikomb, pis'momb, ud'ržitse), но может быть смещен (potvr'eni). Также паерок может быть поставлен на месте, где писец »восстановил« редуцированный гласный, которого этимологически не было (например, второй паерок в слове v'zlûb'lenims между смычным и плавным или в словах ib'ratii, d'ruga и т. п.). Паерок может стоять в середине слова, в середине морфемы (pis'momь), на стыке морфем (neplod'nimi, z'vrhb) или на стыке слов (v'dragahb, s'desetinami). Паерки ставятся непоследовательно, ср. наличие и отсутствие паерков после предлога $s b$ ( $s$ ' cr(b)kvami s'desetinami $s$ v'rti $s$ vinog'radi s malinami s z(e)mlami s' dubravami i z d'rêvi (...) s' pašami (...) s vodami is malini i s puti i s'tazami i sa vsêmi druzimi zak(o)ni i tvrdinami i slobodami svoimi). 
Паерок (вариант 2)

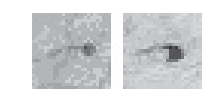

Рис. 74. Паерок (вариант 2)

Fig. 74. Paerok (variant 2)

Второй вариант паерка представляет собой горизонтальную, четко прорисованную линию с обращенным вниз крючком на конце.

Титло ${ }^{16}$

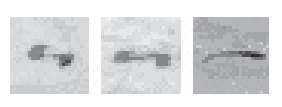

Рис. 75. Титло

Fig. 75. Titlo

Титло представляет собой небольшую горизонтальную линию с насечками с обеих сторон, левая из которых смотрит вверх, а правая - вниз. В последней, пятой, части текста (хотя изредка встречается и в первой половине текста) появляется начертание титло в виде длинной, горизонтальной, слегка изогнутой линии без насечек, иногда с более выраженным завершением (при этом »классическое« начертание продолжает использоваться).

Титло над $e_{\mathrm{PRS} .3 \mathrm{sg}}$

Этот знак представляет собой четко очерченную точку без намека на линию, расположенную над буквой слева. Два раза встречается над графемой (е) в форме PRS.3SG глагола biti (строки 9 и 15).

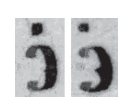

Рис. 76. Титло над $e_{\text {PRs.3sG }}$

Fig. 76. Titlo above $e_{\mathrm{PR} .3 \mathrm{ss}}$

По В. Ягичу (ÂGIČ 1911: 216), такое начертание могло означать формy PRS.3SG глагола biti под титлом, в которой титло »сократилось« до точки. ${ }^{17}$

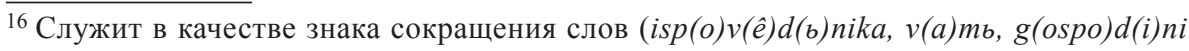
и т. п.).

17 Подобные точки встречаются в тексте и в других словах, но их функцию определить не представляется возможным, и во всех случаях, кроме употребления с глаголом biti, мы склонны принимать их за дефект пергамента или капли чернил (s'dubra(.)vami, slobod(.)ami и т. д.). 


\section{Помарки}

Наконец, элемент в 25 строке над словом nap[o]lahku, вероятно, является помаркой.

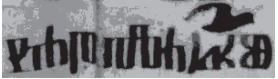

Рис. 77. Форма nap [o]lahku с помаркой

Fig. 77. Form nap [o]lahku with a blot

\section{3. ВЫВОДЫ}

\section{1. Общая характеристика письма}

В целом письмо буллы можно охарактеризовать как пример развитого глаголического устава XIV-XV вв. К его основным особенностям относится отсутствие округлых элементов у $t, v$ и $d$, ломаная правая боковая линия у $\check{c}$ и $\hat{e}$, острый нижний угол у $c$, непосредственное примыкание сегмента к мачте у $g$ и $h$, прямоугольный сегмент у $s, b$ во всю высоту строки, употребление $\ddot{i}$ только в числовом значении и обозначение верхней и нижней линий строки (ŠTEFANIĆ 1969: 12-15).

\section{2. Сопоставление с датированными хорватскими глаголическими рукописями, связанными с Орденом паулинов}

Сопоставление списка буллы с датированными хорватскими глаголическими рукописями, имеющими отношение к Ордену паулинов, носит предварительный характер. Его задача - обратить внимание на проблему отсутствия на данный момент надежных палеографических критериев, позволяющих достаточно узко датировать глаголический памятник или связать его с той или иной локальной традицией.

\subsection{1. Парижский сборник 1380 г.}

Парижский сборник 1380 г. (Paris, BNF, Code Slave 11), созданный в тот же период, что и, возможно, перевод буллы, рядом исследователей также связывается с Орденом паулинов (MILČETIĆ 1911: 80; PUTANEC 1962: 409). ${ }^{18}$ Содержание памятника - литургические тексты (бревиарий, миссал и ритуал) и старейшее собрание духовных песен (хорв. Pariška pjesmarica). Сборник, как и булла, написан глаголическим уставом. К важнейшим отличиям относится наличие графемы »)ิ« (ср., например,

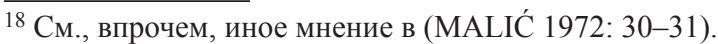


форму ugajâutb, л. 125v). В целом письмо сборника менее торжественное: для букв характерен небольшой наклон, овал у »s« смещен влево, нижний сегмент у »g《 и »h« не прилегает вплотную к мачте. При таком сравнении, конечно, нужно принимать во внимание существенные различия в жанре и объеме обоих памятников, поэтому вопрос об их соотнесении с одной рукописной школой или традицией требует дальнейшего изучения с привлечением материала других уровней языка.

\subsection{2. Второй Новлянский бревиарий 1495 г.}

Другая рукопись, предназначавшаяся для монастыря паулинов, но созданная более чем на сто лет позже Парижского сборника, - Второй Новлянский бревиарий (Novi Vinodolski, Župni ured) (BADURINA-STIPČEVIĆ 2008: 287-288). Подробное палеографическое описание памятника было выполнено в (PANTELIĆ; NAZOR 1977: 12-18). Подобно Парижскому сборнику, графический инвентарь Второго Новлянского бревиария содержит графему »)ی, употребляющуюся преимущественно в заимствованных словах (cp. an' ’’lb, levjiti и т. п.). В остальном, с точки зрения общего облика письма, принципиальных различий между графикой буллы и бревиария, независимо от конкретного писца, нет. Следовательно, если terminus ante quem создания списка буллы определяется годом написания латинского оригинала, то нижняя граница этого периода, по данным графико-палеографического анализа, может существенно выходить за рамки конца XIV в.

\section{3. Заключение}

Формальное описание рукописи буллы папы Григория XI Ордену паулинов позволяет провести несомненные параллели с глаголическими памятниками $\mathrm{XIV}-\mathrm{XV}$ вв. и охарактеризовать ее письмо как один из самых красивых примеров глаголического устава этого периода. ${ }^{19} \mathrm{~B}$ то же время сравнение с двумя датированными рукописями, имеющими отношение к паулинам, показывает, что на основании одного графико-палеографического анализа памятник не может быть непосредственно связан ни с одной из них, а его датировка колеблется между концом XIV и концом XV вв. Более точное определение места и времени возникновения сохранившегося списка буллы будет возможно по мере исследования других языковых уровней и выработки критериев, дифференцирующих глаголическое письмо в рамках указанных временных и территориальных границ.

${ }^{19}$ Cр., например, снимки памятников в AFANAS'EVA; KOZAK; SOBOLEV 2016; VAJS 1932: 148: Ватиканского миссала XIV в., Миссала князя Новака 1368 г., Реймсского евангелия XIV в., отрывка миссала XV в. из собрания Берчича, Сборника Колунича 1486 г. и др. 


\begin{tabular}{|c|c|c|c|c|c|}
\hline Графема & Изображение & Транслитерация & Графема & Изображение & Транслитерация \\
\hline h & th & $\mathrm{a}$ & एा & $\mathbf{M} \|^{\circ}$ & $\mathrm{p}$ \\
\hline щ & $H^{\mu}{ }^{\mu}$ & $\mathrm{b}$ & Б & & $\mathrm{r}$ \\
\hline 띠 & [ill ${ }^{\circ}$ & $\mathrm{v}$ & $\mathbb{Q}$ & TPQ & $\mathrm{s}$ \\
\hline qa & In & $\mathrm{g}$ & ाరा & - IIU UI & $\mathrm{t}$ \\
\hline IIb & Ibdh & d & 刃 & di) & $\mathrm{u}$ \\
\hline 3 & & $\mathrm{e}$ & Ф, 䟚 & $\phi$ & $\mathrm{f}$ \\
\hline 而 & 页! & $\check{Z}$ & la & h & $\mathrm{h}$ \\
\hline 吊 & - & 3 & 또 & - & ô \\
\hline 加 & Dn & $\mathrm{z}$ & 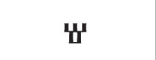 & 4 & $\hat{\mathrm{c}}$ \\
\hline 安 & up & $\ddot{i}$ & v & $q$ & $\mathrm{c}$ \\
\hline 罗 & - & $\ddot{i}$ & 安 & 48 & $\check{c}$ \\
\hline 8 & पy 8 & $\mathrm{i}$ & Ш & 11 & $\breve{s}$ \\
\hline IIP & - & $\hat{\jmath}$ & 咁, 由 & - & $\mathbf{b}$ \\
\hline 4 & & $\mathrm{k}$ & 매8 & - & $\mathrm{bi}$ \\
\hline 孟 & Itt & 1 & 매포, 咁罢 & - & ъï \\
\hline$m$ & & $\mathrm{~m}$ & 由, I, ' & 1 & $\mathrm{~b}$, \\
\hline$P$ & $\boldsymbol{P} \mathbb{P}$ & $\mathrm{n}$ & $B$ & At & $\hat{\mathrm{e}}$ \\
\hline $\mathrm{g}$ & gy & o & 四 & W & $\hat{\mathrm{u}}$ \\
\hline
\end{tabular}

Таблица 3. Буквы

Table 3. Letters 


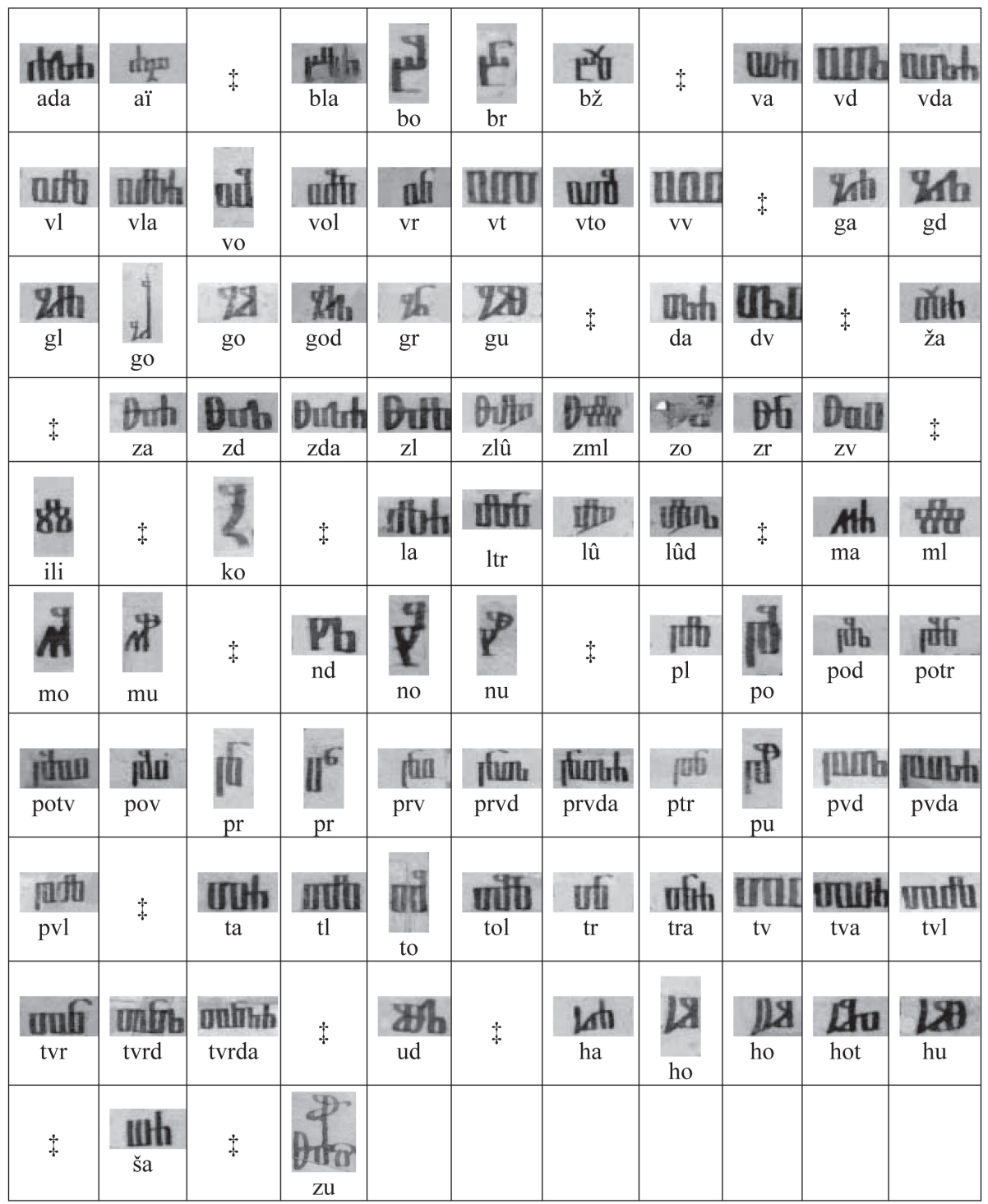

Таблица 4. Лигатуры

Table 4. Ligatures 


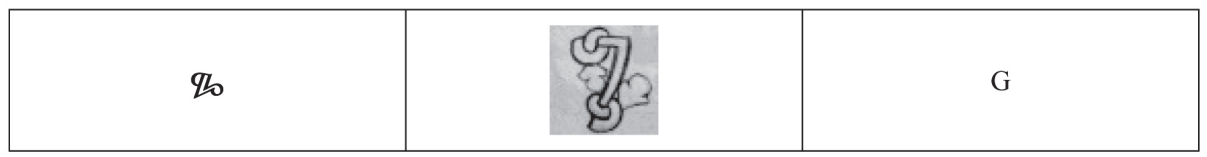

Таблица 5. Инициал

Table 5. Initial

\begin{tabular}{|c|c|c|}
\hline h & hiti & a \\
\hline Һם (лигатура) & id & go \\
\hline Б & 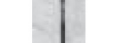 & $r$ \\
\hline
\end{tabular}

Таблица 6. Декоративные буквы

Table 6. Decorative letters

\begin{tabular}{|c|c|c|c|}
\hline Знак & Изображение & Знак & Изображение \\
\hline Параграф & & Титло над $e_{\mathrm{PRS} .3 \mathrm{sg}}$ & 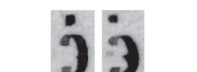 \\
\hline Паерок & $\Rightarrow \quad>\rightarrow \rightarrow$ & Титло & 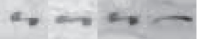 \\
\hline Помарка (?) & Thh! & Точка & - \\
\hline
\end{tabular}

Таблица 7. Надстрочные знаки и знаки пунктуации

Table 7. Diacritical and punctuation signs 


\section{ИСТОЧНИКИ}

BPG = Bula pape Grgura XI. pavlinima / Булла папь Григория ХI Ордену св. Павла Отшельника (Ордену паулинов), ок. 1371 г., Загреб, Коллекция рукописей и старых книг Национальной и университетской библиотеки Загреба (шифр R 4476).

\section{ЛИТЕРАТУРА}

AFANAS'EVA; KOZAK; SOBOLEV 2016. = АФАНАСЬЕВА, Т. И.; В. В. КОЗАК; А. Н. СОБОЛЕВ. 2016. Глаголическая письменность Западных Балкан X-XVI веков: учебно-методическое пособие. Санкт-Петербург: Наука. [AFANAS'EVA, T. I.; V. V. KOZAK; A. N. SOBOLEV. 2016. Glagoličeskâ̂ pis'mennost' Zapadnyh Balkan X-XVI vekov: učebno-metodičeskoe posobie. Sankt-Peterburg: Nauka.]

ÂGIČ 1911. = ЯГИЧ, В. 1911. Эничклопедія славянской Филологіи. Выпуск 3: Графика у Славянъ. Санкт-Петербург: Типографія Императорской академіи наукъ. [ÂGIČ, V. 1911. Ènciklopediâ slavânskoj Filologii. Vypusk 3: Grafika u Slavân". Sankt-Peterburg: Tipografiâ Imperatorskoj akademii nauk".]

BADURINA-STIPČEVIĆ, V. 2008. Translacija sv. Pavla Pustinjaka u hrvatskoglagoljskom II. Novljanskom brevijaru iz 1495. godine. Slovo 58: 285-312.

BÈSJA 1998. = БЭСЯ 1998. Большой энияилопедический словарь: Языкознание. В. Н. Ярцева (ред.). Москва: Научное издательство »Большая Российская энциклопедиящ. [BËSẦ 1998. Bol'šoj ènciklopedičeskij slovar': Âzykoznanie. V. N. Ârceva (red.). Moskva: Naučnoe izdatel'stvo »Bol'šaâ Rossijskaâ ènciklopediâu.]

BOGOVIĆ, M. 1988. Pavlini u Senju. Senjski zbornik 15/1: 109-120.

DAMJANOVIĆ, S. 2009. Staroslavenski i starohrvatski u srednjovjekovnim hrvatskim tekstovima. S. Damjanović (ur.). Povijest hrvatskoga jezika. 1. knjiga: srednji vijek. Zagreb: Društvo za promicanje hrvatske kulture i znanosti CROATICA, 351-403.

GOLYŠENKO 2010. = ГОЛЫШЕНКО, В. С. 2010. Палеографическое описание Типографского Евангелия XII в. Лингвистическое источниковедение и история русского языка (2006-2009): 5-37. [GOLYŠENKO, V. S. 2010. Paleografičeskoe opisanie Tipografskogo Evangeliâ XII v. Lingvističeskoe istočnikovedenie $i$ istoriâ russkogo âzyka (2006-2009): 5-37.]

HERCIGONJA, E. 1975. Povijest hrvatske književnosti. Knj. 2. Srednjovjekovna književnost. Zagreb: Liber-Mladost.

KUZMIĆ, B. Jezik hrvatskih srednjovjekovnih pravnih spomenika. S. Damjanović (ur.). Povijest hrvatskoga jezika. 1. knjiga: srednji vijek. Zagreb: Društvo za promicanje hrvatske kulture i znanosti CROATICA, 405-455.

MALIĆ, D. 1972. Jezik prve hrvatske pjesmarice. Zagreb: Liber.

MALLECHICH, C. (ed.). 1708. Quadripartitum regularium, in quo primo de privilegiis in communi, secundo de privilegiis particularibus ordinis $S$. Pauli primi eremitae, tertio de privilegiis ejusdem ordinis, per viam communicationis cum patribus Carthusiensibus, quarto de privilegiis et juribus regularium in genere et in specie, 
perbullas \& constutiones Romanorum pontificum, eorum ampliativas, restrictivas ac declarativas, tractatur. Viennae: Typis Annae Franciscae Voigt Viduae.

MARTI, R. 2014. Historische Graphematik des Slavischen: Glagolitische und kyrillische Schrift. K. Gutschmidt, S. Kempgen, T. Berger, P. Kosta (Hrsg.). Die slavischen Sprachen. The Slavic Languages. Ein internationales Handbuch zu ihrer Struktur, ihrer Geschichte und ihrer Erforschung (Handbücher zur Sprach- und Kommunikationswissenschaft, Bd. 32.2). An International Handbook of their Structure, their History and their Investigation (Handbook of Linguistics and Communication Science 32.2). Berlin: Mouton de Gruyter, 1497-1513.

MILČETIĆ, I. 1911. Hrvatska glagoḷska bibliografija. 1. dio. Opisi rukopisa. Starine JAZU XXXIII: 426-431.

MILČETIĆ, I. 1916. Hrvatski prijevod bule pape Grgura XI. pavlinima: regule svetoga Augustina na »Ugrih« i po drugim stranama. Starine JAZU XXXV: 1-505.

PANTELIĆ, M.; A. NAZOR 1977. II. Novljanski brevijar. Hrvatskoglagoljski rukopis iz 1495. Župni arhiv Novi Vinodolski. Fototipsko izdanje. Uvod. Bibliografija. Zagreb Graz: Staroslavenski zavod Svetozar Ritig, Turistkomerc.

PUTANEC, V. 1962. Starohrvatski glagoljski uklin protiv zmija u rukopisu 14. stoljeća. Zbornik za narodni život i običaje južnih Slavena 40: 409-412.

RCJHR 2000 = Rječnik crkvenoslavenskoga jezika hrvatske redakcije. I. sv. $(A-V R \hat{E D D})$ Zagreb: Staroslavenski institut.

ŠTEFANIĆ, V. 1969. Glagoljski rukopisi Jugoslavenske akademije. Dio 1. Uvod, Biblija, apokrifi i legende, liturgijski tekstovi, egzorcizmi i zapisi, molitvenici, teologija, crkveni govori (homiletika), pjesme. Zagreb: Historijski institut Jugoslavenske akademije znanosti i umjetnosti.

VAJS, J. 1932. Rukovět hlaholské paleografie. Uvedeni do knižního písma hlaholského. Praga: Nákl. Slovanského ústavu; v komisi Orbis.

ŽAGAR, M. 2013. Uvod u glagoljsku paleografiju 1 (X. i XI st.). Zagreb: Institut za hrvatski jezik i jezikoslovlje. 


\title{
Sažetak
}

\author{
Diana Dimitrievna Balaševič, Vâčeslav Viktorovič Kozak, \\ Andrej Nikolaevič Sobolev
}

\section{PALEOGRAFSKI OPIS HRVATSKOGLAGOLJSKE BULE PAPE GRGURA XI. REDU SV. PAVLA PUSTINJAKA}

Papa Grgur XI. stavio je svoj potpis na latinski tekst konzistorijalne bule kojom se utvrđuju prava i privilegije Reda sv. Pavla Pustinjaka (pavlinskoga reda) u Avignonu 1371. godine. Hrvatski prijevod bule vjerojatno je nastao u jednom od pavlinskih samostana srednjovjekovne Hrvatske. Jedini sačuvani glagoljski prijepis prijevoda čuva se u Zbirci rukopisa i starih knjiga Nacionalne i sveučilišne knjižnice u Zagrebu (sign. $R$ 4476). U rukopisu nema podataka o mjestu i vremenu nastanka, ali se smatra da je nastao sedamdesetih godina XIV. stoljeća. U ovome radu, koji je nastao tijekom priprema za novo izdanje teksta hrvatskoga prijevoda bule, daje se opis njegovih paleografskih osobina. Razmatra se oblik malih, velikih i ukrasnih grafema, ligatura, inicijala, nadrednih i drugih znakova. Građa se prikazuje tabelarno. Iako paleografski opis rukopisa omogućuje da se istaknu nesumnjive paralele s glagoljskim spomenicima XIV. - XV. stoljeća, ipak će preciznije određivanje mjesta i vremena nastanka sačuvanoga prijepisa bule biti moguće tek nakon što se istraže druge jezične razine teksta te utvrde kriteriji prema kojima se glagoljsko pismo diferencira u okvirima navedenih vremenskih i prostornih granica.

Ključne riječi: paleografija, uglata glagoljica, bula, Grgur XI., XIV. stoljeće, Hrvatska, pavlini

\section{Summary}

\section{Diana Dimitrievna Balaševič, Vâčeslav Viktorovič Kozak, Andrej Nikolaevič Sobolev}

\section{PALEOGRAPHIC DESCRIPTION OF THE CROATIAN GLAGOLITIC BULL OF POPE GREGORY XI TO THE ORDER OF ST. PAUL THE FIRST HERMIT}

The Latin text of the consistory bull regulating the rights and privileges of the Order of Saint Paul the First Hermit (the Pauline Order) has been signed by Pope Gregory XI at Avignon in 1371. Its Croatian translation was carried out probably in one of the Pauline monasteries of medieval Croatia. Its only preserved Glagolitic copy is kept in the Manuscripts and Old Books Collection of the National and University Library of Zagreb $(R$ 4476). The manuscript does not contain information on the place and time of its creation and it is usually dated to $1370 \mathrm{~s}$. In this paper, which resulted from the preparation work of a new edition of the manuscript, its paleographic features (uppercase, lowercase and decorative graphemes, initial, supralinear and linear marks) are described. Summary tables are provided. The paleographic description of the manuscript permits to draw parallels with the Glagolitic monuments from the 14th-15th centuries. However, for a more accurate dating and localization of the translation, it is necessary to study its language and develop appropriate paleographic criteria.

Keyw ords: paleography, Glagolitic alphabet, bull, Gregory XI, 14th century, Croatia, Pauline order 